\title{
Determining the qualitative working indices for various forms of the active body of a rut soil compartmentation equipment
}

\author{
Marius Remus Oprescu ${ }^{1 *}$, Iuliana Gageanu ${ }^{1}$ and Mario Cristea ${ }^{1}$ \\ ${ }^{1}$ National Research - Development Institute for Machines and Installations Designed to Agriculture \\ and Food Industry, 6 Ion Ionescu de la Brad Blv., 013813 Bucharest, Sector 1, Romania
}

\begin{abstract}
The subdivision of ruts represents the process of periodic formation between their ridges of small soil dams, small pools of water accumulation created in the processed soil with the help of equipment to open watering channels in order to reduce the phenomenon of erosion and to make more efficient use of the water from precipitation or by using sprinkler systems. This is a method of soil and water conservation that is used on inclined lands with a slope of less than $6^{\circ}$ or on disturbed land. The practice began to be widely adopted following the use of new herbicide technologies necessary for weed control but also for improving the mechanical equipment for dam construction. In this paper are presented the results obtained from the optimization of the dimensions and the shape of the working body of the PCVM2,2 + EMBC2 equipment used in the compartmentation of the ruts in the vine-apple orchards with calculation of the qualitative indices of obtained work.
\end{abstract}

Key words: compartmentalized rut, erosion, water, active organ optimization, qualitative indices of work

\section{Introduction}

The soil represents the layer from the surface of the earth's crust and is composed of mineral particles, water, air, organic matter and living organisms. It is a non-renewable resource located at the intersection of land, water and air and fulfils a number of vital functions: the production of food or biomass, source of biodiversity, habitats, species and genes, storage and transformation of many substances, source of raw materials, heritage geological and archaeological, carboniferous basin, serves as a platform or physical environment for humans and human activities. The capacity of the land is limited and the demand for natural resources from society is increasing [1,6]. Water has been identified as one of the scarce resources, which can severely restrict and even compromise agricultural production and productivity, unless is carefully managed and conserved. [13]

In the case of sloping ground, the rainwater flows to the soil surface, thus not being used by plants and at the same time causing soil degradation through erosion, an extremely serious process encountered on one third of the agricultural surface of the country and at the bottom accumulating excess water which causes flooding of plants $[1,6,15]$.

\footnotetext{
*Corresponding author: oprescu.remusmarius@gmail.com
} 
Recent climate change has the potential to affect agricultural production due to changes in temperature and precipitations. Changes in the distribution and quantities of precipitation are of the most critical factors that influence the global climate. Under these conditions, the need arises to develop new technologies that increase the efficiency of the use of rainwater and to support the quality of the soil and the environment in order to obtain the most profitable agricultural products. Current scenarios predict that climate change will increase the water shortage in Southern Romania [1].

In the southern part of Romania, characterized by a temperate continental climate, there is a need to conserve "in-situ" soil moisture due to insufficient rainfall for agriculture [9]. Rainwater collection has the potential to reduce soil erosion and improve the productivity of these areas. Rainwater harvesting is a general term used to describe the collection and concentration of surface runoffs for various uses, including for agricultural and household use [2].

Sloped agricultural areas can lose much of the water from precipitation by surface runoff and large amounts of soil by erosion. The process of soil loss due to erosion has been increasingly studied in recent times [5].

The interrupted watering furrows are necessary on lands with slopes or slopes that cause the drainage and accumulation of water in micro-depressions, lands that have been arranged for irrigation by sprinkling, using fixed or mobile installations [8].

The "in situ" systems, Figure 1, are the simplest and the cheapest approaches for rainwater harvesting and can be practiced in many agricultural systems. Also called water conservation works systems, they involve the use of methods to increase the amount of water stored in the soil profile by capturing or maintaining water from precipitation $[3,8,10]$. Higher infiltration also means higher soil moisture content. Increased soil water content allows optimal plant development [5]. Studies establishing empirical equations to estimate the conservation efficiency of compartmentalized furrows have been conducted $[11,12]$.

The use of compartmentalised furrows in semi-arid areas has significantly influenced agricultural production [4].

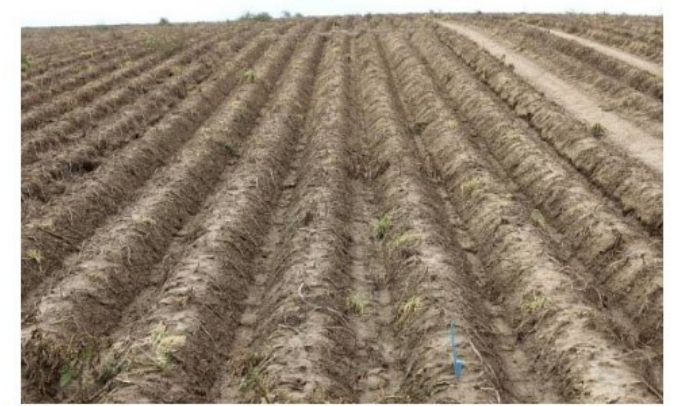

Fig. 1. Comparison of plot without micro-dams (left) and plot with micro-dams (right) at the end of the season [15].

In the case of irrigated crops, developing optimal water management for irrigation is important for water productivity and improving food security. Therefore, the introduction of knowledge on the need for water for crop irrigation is essential [5,9].

In the paper are presented the results obtained from the optimization of the dimensions and the shape of the working body of the PCVM2,2 + EMBC2 equipment used in the compartmentation of ruts in the vine-apple orchards with calculation of the qualitative indices of obtained work. 


\section{Material and method}

The equipment for moulding the soil in compartmentalised furrows in vine-orchard plantations., PCVM2,2+EMBC2-0 (Figure 2) performs compartmentalized furrows at vine-tree plantations, in order to accumulate water from rainfall in the soil on which the drops fall, thus avoiding the flow of water outside the cultivated perimeter or accumulation in depressive areas, on lands with slopes up to $5 \%$, on soils with light, medium or heavy texture, at a depth of at least $250 \mathrm{~mm}$, at a moisture close to the minimum threshold.

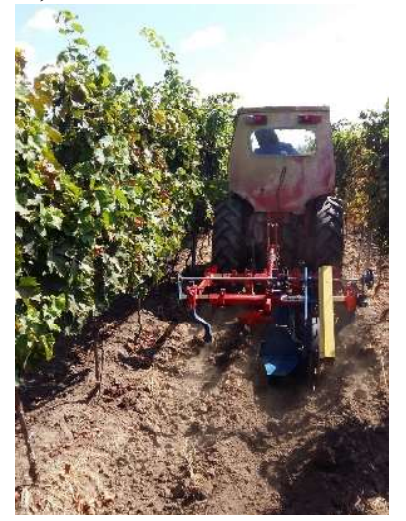

Fig. 2. Device testing at the Murfatlar Vineyard Research and Development Station [14]

The equipment for moulding the soil in compartmentalized furrows at vine-orchard plantations, PCVM2,2 + EMBC2-0 has the following main subassemblies: a clearance lister, a device for realizing compartmentalized furrows provided with a control mechanism and optionally two arrow blades if hoeing is desired.

Constructive description of the device for making compartmentalized furrows (Figure 3) consists in the following main parts: control mechanism, rotor support, pallet rotor and grounding mechanism of the racquet pallet. Adjusting the furrow compartmenting mechanism will allow for soil dams along the fence at distances of $1.5 ; 3$ or 6 .
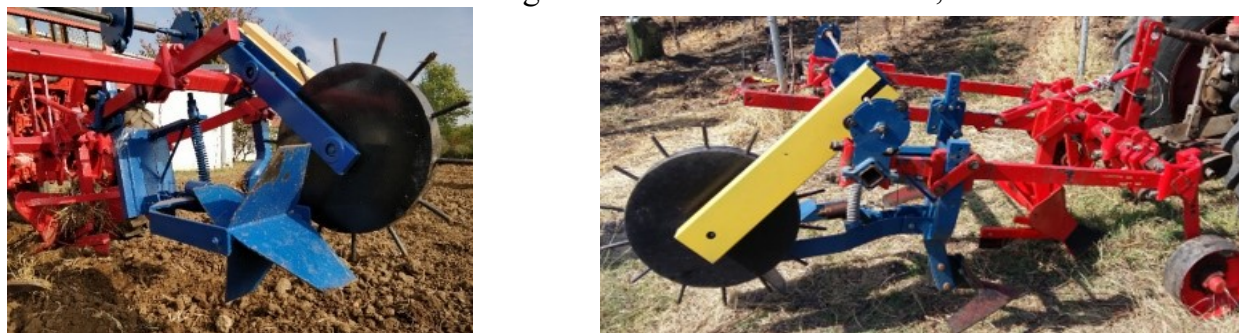

Fig.3. Device for making compartment furrows

The control mechanism consists of: wheel with spur, a transmission and drive mechanism.

Wheel with spurs is metallic and provided with steel spurs on the hoop, with the role of increasing the adhesion of the wheel to the ground, thus avoiding its skidding. The wheel with spurts will be mounted articulated at the rear central part of the frame, having the possibility of vertical oscillation around the axis that drives the cams, in order to copy the land in the working process. For the transport position, the spinning wheel will be fixed upright.

Transmission it is of the chain type and has the role of transmitting the movement from the spinning wheel to the camshaft axle. The transmission consists mainly of: support, chain wheels, 10 A chain and mudguard. 
The drive mechanism (Figure 4) has the role of unlocking the pallet rotor to form the ground plug on the furrow. It is composed of the following main parts: - camshaft holder, in 3 pieces ( 2 cams and one piece for the wheel with spurs); - cam wheel; - lever / cable and locking bolt.

Fig. 4. Drive mechanism.

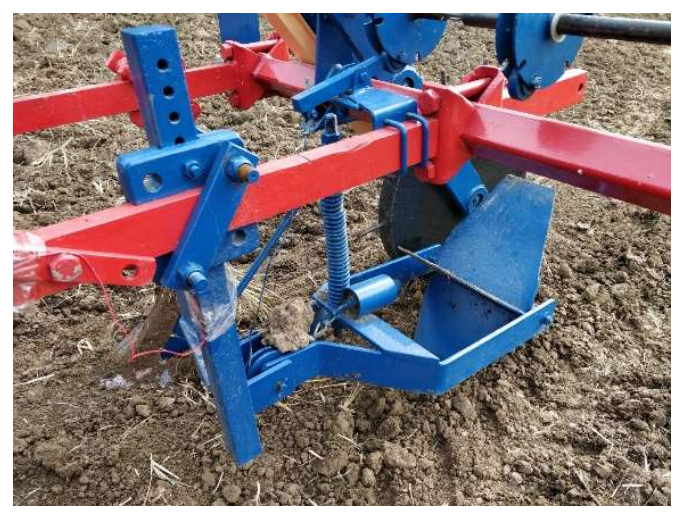

In Figure 5 is presented the kinematic diagram of the fencing compartment equipment.

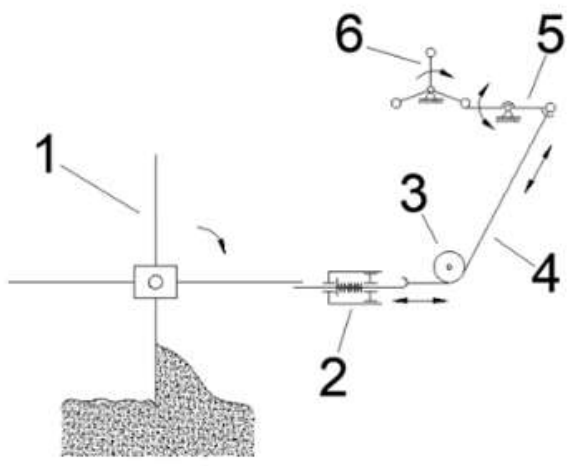

Fig. 5. Kinematic schematic of split compartment equipment.

1-pallet rotor, 2-locking element, 3-roller, 4-cable, 5-lever, 6- cam

The camshaft supports are mounted on the rear bar of the frame, behind the body and the camshaft and the lever will be mounted on the support. The steering wheel bracket is mounted on the bar behind the frame in the central position, in the direction of the steering wheel.

The cam wheel is made from a disc parallel to the bearing disc and the cam wheel is mounted on the cams (1,2 or 3$)$, depending on the distance chosen to make the bushing compartment stops. The lever is mounted articulated on the support, in the direction of the cams and has at one end a roller and at the other end a bolt for fixing the steel cable. The cable has the role of transmitting the movement from the lever driven by the cam, to the locking pin of the rotor with pallets. The locking ratchet is made from an axis, with a welded plate at the end. The shaft slides into two translation couplings represented by two steel bushes fixed on the rotor support. An arc is mounted on the shaft which compresses when the lock mechanism is actuated and helps to lock the pallet when the control mechanism does not operate. The trigger mechanism operates safely and without locking.

The rotor support it is mounted on the sidebar of the frame, behind the body. The support consists of a vertical support, a fork and a support bar for the spring that presses the 
pallet rotor on the ground. The fork is hinged to the upright support, can swing freely vertically and supports the pallet rotor, the lower end of the spring of the squeegee pallet in the ground and the axle guide bushings of the rotor lock ratchet.

The rotor consists of 4 pallets of pentagonal shape arranged on an axis, the angle between 2 adjacent pallets has the value $90^{\circ}$. The pallets have the vertical outer side, a position that facilitates the approach of the working section to the plant row without the pallets damaging the plants.

The spring pressing the scraper pallet on the soil is mounted by means of a steel rod between the rotor support fork and the bar provided on the vertical support.

\section{Working conditions}

The experiments under operating conditions for determining the qualitative indices, were performed on the experimental group belonging to INMA-Bucharest. The research was carried out in a soil following a corn crop, the Universal 445-L tractor was used; The working speed was between $2.1 ; 2.5 ; 3.1 \mathrm{~km} / \mathrm{h}$; the working width was $1400 \mathrm{~mm}$; the soil was of the chernozem type; main preliminary works consisted of ploughing and discussing; the dimensions of the initial rotor blade were: $260 ; 120 ; 260$; and after optimization were: $400 ; 200 ; 260$.

\section{Determining the optimum section of the watering channel}

In order to accumulate as much water as possible, it is necessary to have a surface as large as possible under the required conditions. In the case of watering furrows, the section has the form of a trapeze and in order to have minimal expenses, the surface of the trapeze must be maximum at a given perimeter. The perimeter used consists of the small base and the two oblique sides, Figure 6.

In order to express the function [11] in relation to the parameters of the problem, the following data are used: relation 1 is the area of the trapezoid section; relation 2 is the perimeter used, $\alpha$, the angle between the large base B and the side 1 .

$$
\begin{aligned}
& S=\frac{(B+b) h}{2} \\
& P=2 l+b
\end{aligned}
$$

The dimensions of the side $I$ and the angle $\alpha$ are required so that the section of the trapezoid is maximum.

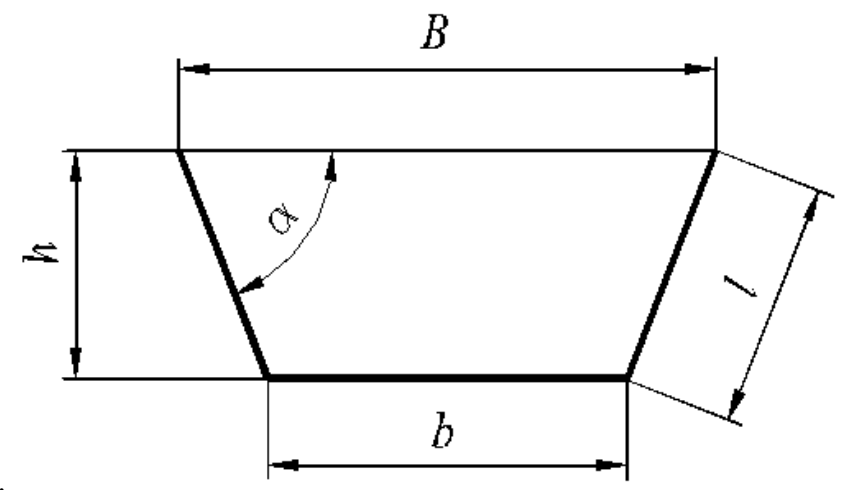

Fig. 6. The shape of the section of a channel

For a given perimeter $P$, the two variables are:

and the maximum section is:

$$
\begin{array}{ll}
l=0.333333 \cdot P & {[\mathrm{~m}]} \\
\alpha=1.047197 & {[\mathrm{rad}]}
\end{array}
$$

$$
S=0.144338 \cdot P^{2}\left[m^{2}\right]
$$


In this case we have $\mathrm{h}=0.17 \mathrm{~m}$, therefore:

Results:

$$
l=\frac{h}{\sin \alpha}=\frac{0,17}{0,866}=0,1963 \quad[\mathrm{~m}]
$$

$$
\begin{aligned}
& b=l \cong 0,2 \quad[\mathrm{~m}] \\
& B=2,1=0,4 \quad[\mathrm{~m}]
\end{aligned}
$$

The optimum width of the watering channel in the case of sowing crops sown at a distance between rows of $0.6 \mathrm{~m}$ so that the roots of the plants are not affected is $0.4 \mathrm{~m}$.

\section{Qualitative work indices for the dimensions of the rut made with the pallet rotor before and after optimization}

During the tests under operating conditions, the procedures specific to the testing of the soil modelling devices were used and the following metrologically verified measuring and control devices and equipment were used: digital penetrometer with Fieldscout SC900 cone, portable HH2 moisture meter with Theta sensor ML2X samples, mechanical tape measure, mechanical chronometer, furrow-meter, rulers, square rulers, ranging rods. The soil moisture and compaction were determined at the time of testing and qualitative indications of work for the dimensions of the gullet made with the rotor with blades (Figure 7).

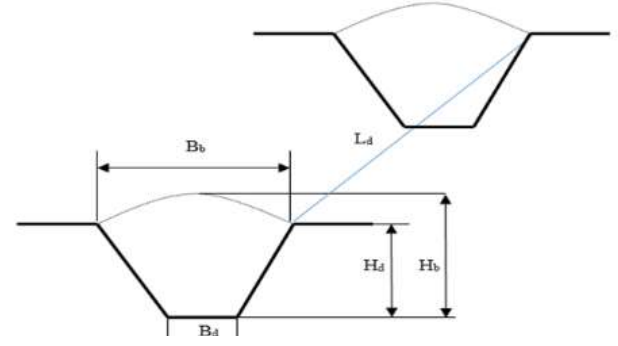

Fig. 7. The dimensions of the rut made with the rotor with blades.

( $H b$ - the depth of the watering channels, $B d$ - the width of the bottom of the furrow, $B b$ - the upper width of the furrow, $H d$ - the height of the dam, $L d$ - the distance between the dams.

Aspects from determining the qualitative indices of work are shown in Figures 8 and 9.

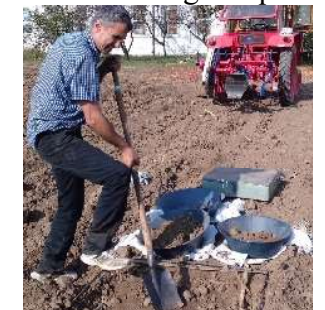

Fig. 8. a Determining the degree of ground clearance.

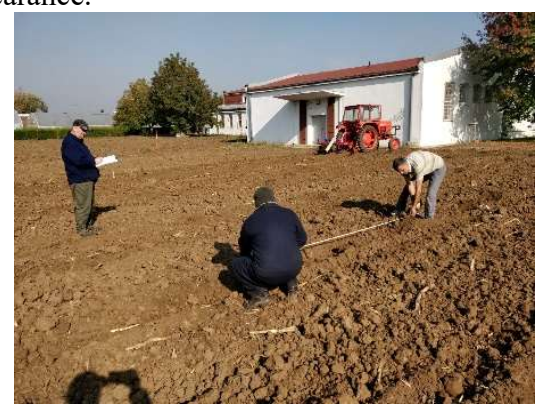

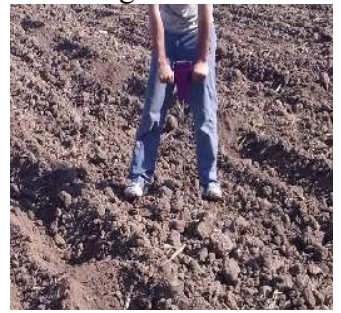

Fig. 8. $b$ Determining the compactness of the terrain of the land.

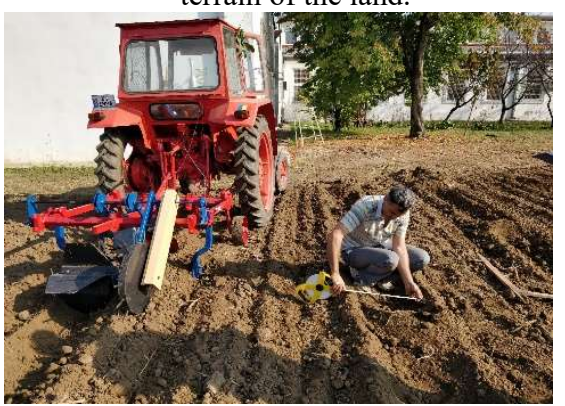


Fig. 9. Determining qualitative indices.

The following measuring and control devices and equipment were used to determine the degree of ground clearance: sieve with $80 \mathrm{~mm}, 50 \mathrm{~mm}, 20 \mathrm{~mm}$ holes; $160 \mathrm{~kg}$ mechanical scale; metric frame; row.

The procedure for determining the degree of ground clearance is carried out as follows: at a distance of at least $20 \mathrm{~m}$ from the end of the plot, the metric frame is thrown and the surface of $1 \mathrm{~m}^{2}$ is marked. Clogs larger than $100 \mathrm{~mm}$ are chosen and weighed and the rest of the soil, until the bottom of the furrow is taken with a shovel and passed in stages through the $80 \mathrm{~mm}, 50 \mathrm{~mm}$ and $20 \mathrm{~mm}$ sieves. All the fractions of the soil are summed and the percentage for each fraction is individually calculated: $>100 \mathrm{~mm} ; 80-50 \mathrm{~mm} ; 50-20 \mathrm{~mm}$ and $<20 \mathrm{~mm}$. The procedure is repeated three times to obtain the most accurate results.

In Figure 10 are presented the four versions of blades with which the rotors were equipped and for which qualitative indices were determined for the equipment to open and compartmentalize the watering furrows.

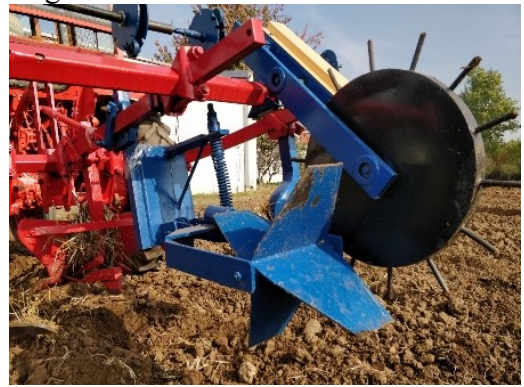

a) straight blades with which the equipment was equipped until optimization

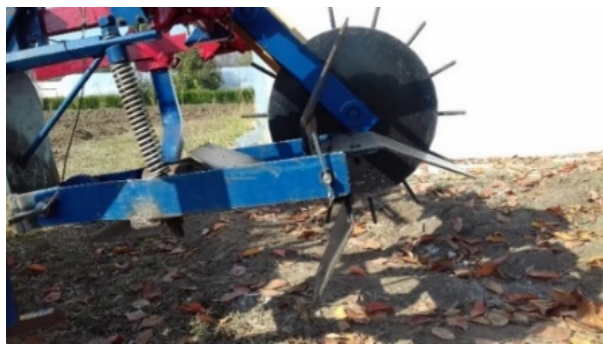

c) inclined blade with optimized dimensions

Fig. 10. Types of blades.

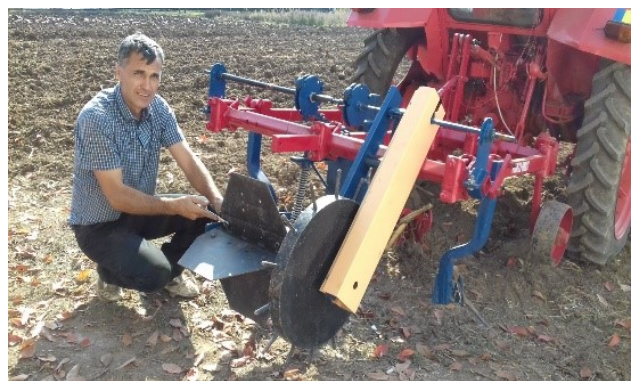

b) straight blade with optimized dimensions

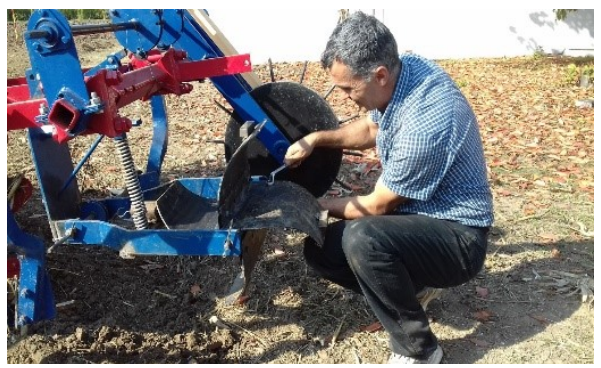

d) curved blade with dimensions after optimization

\section{Results and discussions}

Tables 1 and 2 show the results of moisture and penetration resistance of the soil used for experiments.

Table 1. Soil moisture.

\begin{tabular}{|c|c|c|c|c|c|c|}
\hline $\begin{array}{l}\text { Volumetric } \\
\text { moisture, } \\
\text { depth, cm }\end{array}$ & \multicolumn{6}{|c|}{ Value / measurement points } \\
\cline { 2 - 7 } & $\mathbf{1}$ & $\mathbf{2}$ & $\mathbf{3}$ & $\mathbf{4}$ & $\mathbf{5}$ & Average \\
\hline At surface & 7.6 & 9.8 & 8.4 & 7.9 & 7.2 & $\mathbf{8 . 1 8}$ \\
\hline 10 & 15.4 & 16.7 & 18.1 & 16.1 & 16.8 & $\mathbf{1 6 . 6 2}$ \\
\hline 20 & 19.5 & 18.4 & 21.8 & 18.6 & 19.1 & 19.48 \\
\hline
\end{tabular}


From table 1 it is shown that the moisture of the soil allows the experiments to be conducted under optimal conditions. A high soil moisture creates conditions for its sticking to pallets and therefore the impossibility of testing the equipment.

Table 2. Soil resistance to penetration.

\begin{tabular}{|c|c|c|c|}
\hline \multirow{2}{*}{ Depth, cm } & \multicolumn{3}{|c|}{ Penetration resistance, kN / Sample no. } \\
\cline { 2 - 4 } & $\mathbf{1}$ & $\mathbf{2}$ & $\mathbf{3}$ \\
\hline $\mathbf{0}$ & 16.5 & 17.5 & 17.3 \\
\hline $\mathbf{2 . 3}$ & 17.5 & 18.1 & 17.6 \\
\hline $\mathbf{5 . 0}$ & 22.8 & 21.6 & 22.5 \\
\hline $\mathbf{7 . 5}$ & 38.1 & 28 & 31.5 \\
\hline $\mathbf{1 0 . 0}$ & 58.3 & 50.1 & 54.1 \\
\hline $\mathbf{1 2 . 5}$ & 66.7 & 52.6 & 59.3 \\
\hline $\mathbf{1 5 . 0}$ & 158.2 & 94.7 & 80.2 \\
\hline $\mathbf{1 7 . 5}$ & 177.4 & 138.8 & 147.5 \\
\hline $\mathbf{2 0 . 0}$ & 140.4 & 170 & 155.2 \\
\hline
\end{tabular}

From the analysis of the measured values regarding the soil resistance to penetration in conjunction with the classes of resistance of the soil to penetration (according to Methodology I.C.P.A., 1987) it resulted that in a small percentage the soil is extremely compacted.

Following the procedure for determining the degree of soil grinding on the plot where the tests were performed, the following results were obtained:

- fractions with a size greater than $100 \mathrm{~mm}$, a percentage of $7 \%$;

- fractions with the size in the range of $50-80 \mathrm{~mm}$, a percentage of $12 \%$;

- fractions with the size between 20 and $50 \mathrm{~mm}$, a percentage of $38 \%$;

- fractions less than $20 \mathrm{~mm}$ in size, $43 \%$.

Because the fractions smaller than $50 \mathrm{~mm}$ are in a percentage of more than $80 \%$, is indicated that the soil is sufficiently well-prepared for conducting the measurement in good conditions.

Figure 11 presents the qualitative indices obtained from the tests performed with the four versions of working bodies.

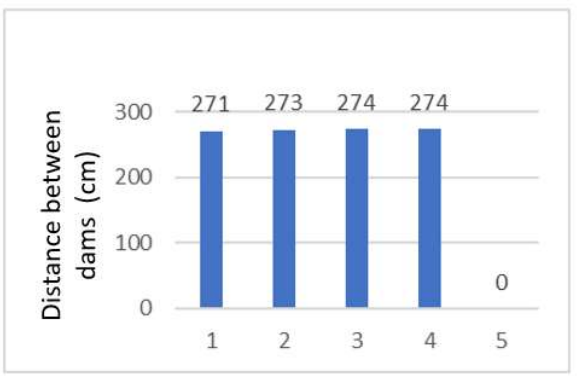

a

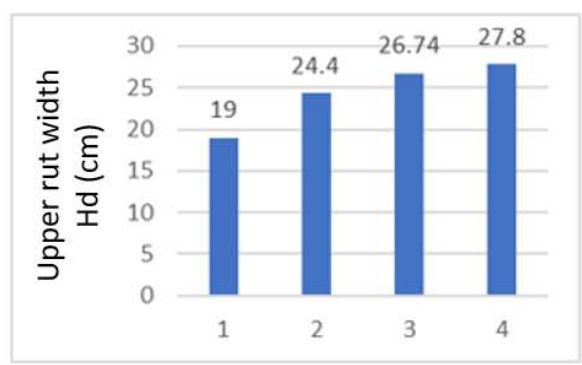

b 


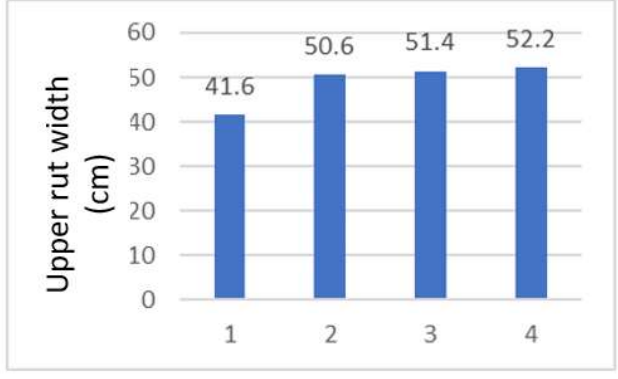

c

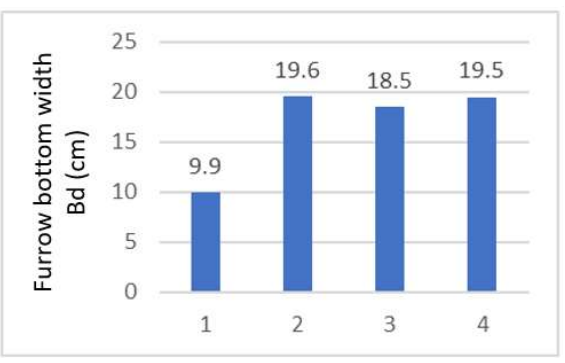

d

Fig. 11. Qualitative indices obtained from the tests.

From Figure 11 a) it is shown that the only dimension that does not change is the distance between the dams. In Figure $11 \mathrm{~b}$ ), the height of the dam is shown, where a significant increase from $19 \mathrm{~cm}$ is observed. for the rotor with the non-optimized straight blade up to $27.8 . \mathrm{cm}$. In the case of the equipment equipped with rotor with curved blades to the dimensions obtained after optimization, a significant increase of about $50 \%$ due to the amount of material accumulated in front of the working body.

The upper width of the dam (Figure $11 \mathrm{c}$ ) has values higher than the size of the working body values obtained with the help of the opening angle of the rut, but in this case, we have differences of about $20 \%$ obtained as a result of changing the dimensions of the blades.

The width of the bottom of the furrow (Figure $11 \mathrm{~d}$ ) varies from simple in the case of the initial equipping of the equipment's rotor to almost double in the case of using blades with the dimensions obtained after optimization (from $9.9 \mathrm{~cm}$ to $19.6 \mathrm{~cm}$ ).

\section{Conclusions}

By measuring the qualitative indices, a significant difference is observed between the dimensions obtained with the initial version and those obtained with the optimized version, highlighting the influence that this dimension has on the volume of water to be stored by the compartmented furrow.

From the presented data, the following conclusions result:

- an increase of the section of the watering channel of more than $200 \%$ following the modification of the dimensions of the working body and taking into account that the distance between the mini dams does not change significantly;

- a volume of water that can be stored between mini dams at least three times larger;

- comparing the height of the mini dam to the three constructive versions of blades made to the dimensions obtained from the optimization calculation results in a higher height in the case of the use of curved blades, therefore an amount of material accumulated in front of the larger working member in their case;

- After testing the operating conditions of the four versions of blades, it was shown that the version in which the curved blade was used obtained the best quality indices.

Following the experiments conducted according to the standards in force, qualitative work indices were obtained that fall within the agrotechnical requirements of the soil modelling work.

This work was supported by Romanian Education and Research Ministry, through Programme 1 - Development of the national research-development system, subprogramme 1.2 - Institutional performance - Projects for financing excellence in RDI, contract no. 16PFE and European Social Fund from the Sectoral Operational Programme Human Capital 2014-2020, through the Financial 
Agreement with the title "Scholarships for entrepreneurial education among doctoral students and postdoctoral researchers (Be Antreprenor!)", Contract no. 51680/09.07.2019 - SMIS code: 124539.

\section{References}

1. A.C. Marica, A. Busuioc, The potential of climate change on the main components of water balance relating to maize crop, Romanian J. Meteor. 6 (1-2), pp. 50-57, (2004)

2. FAO, Soil tillage in Africa: needs and challenges, FAO Soils Bulletin 69. Rome, (1993).

3. G. Brhane, C.S.Wortmann, M. Marno, H. Gebrekidan, A. Belay, Micro basin tillage for grain sorghum production in semiarid areas of northern Ethiopia, Agron. J. 98, pp. 124-128, (2006)

4. Haytham M. Salema,b, Constantino Valero, Miguel Ángel Muñoz ,4 María GilRodríguez-Effect of integrated reservoir tillage for in-situ rainwater harvesting and other tillage practices on soil physical Q1 properties februarie 2015

5. Hintsa Libsekal Gebremariam, Kidane Welde, Kiflom Degef Kahsay Sustainable Water Resources Management, December 2018, Volume 4, pp. 1043-1049

6. 6. I. Biolan, I. Serbu, G.C. Tusa, F. Mardare, Irrigation of agricultural cropsTechnologies, AGIR Publishing House, Bucharest, (2016)

7. I. Rellinia , C. Scopesia , S. Olivarib , M. Firpoa and M. Maerker Assessment of soil erosion risk in a typical Mediterranean environment using a high resolution RUSLE approach JOURNAL OF MAPS 2019, VOL. 15, NO. 2, 356-362

8. M. R. Oprescu, D. N. Dumitru, I. F. Voicea, S. S. Biriş, Considerations regarding the use of the equipment for opening and compartmentalizing the watering furrows, International Symposium ISB-INMA TEH Bucharest 31st October - 1st November, pp. 381-386, (2019)

9. .R. M. Oprescu, I. F. Voicea, I. Dumitru, I. Dragan, C.Biolan, N. Ungureanu, E. A. Neagu, N. Bara , D. Jaloba, V. N. Arsenoaia, Rain Use Efficiency in Southern Romania after Using the Device for Soil Modelling in Interrupted Furrows for Weeding Crops - DMBC-5, E3S Web of Conferences 112, 03005 (2019), https://www.e3s-conferences.org/articles/e3sconf/pdf/2019/38/e3sconf_te-rerd18_03005.pdf

10. S. AN̄DRIEŞ, V.FILIPCIUC (2016) Research in the field of soil erosion

11. Y. Liu, Yan Xin, Y Xie, W. Wang, Effects of slope and rainfall intensity on runoff and soil erosion from furrow diking under simulated rainfall, CATENA,Volume 177, June 2019, Pages 92-100, https://doi.org/10.1016/j.catena.2019.02.004

12. V. Moise, E. Maican, Şt. I. Moses, Numerical Methods. Applications in MATLAB. Printech Publishing House, Bucharest, (2016).

13. T. Gebremedhin, , Ethiopia. Effect of Drip and Surface Irrigation Methods on Yield and Water Use Efficiency of Onion (Allium Cepa L.) under Semi-Arid Condition of Northern Ethiopia Journal of Biology, Agriculture and Healthcare www.iiste.org ISSN 2224-3208 (Paper) ISSN 2225-093X (Online) Vol.5, No.14, 2015

14. https://www.agrofood.ro/Article-Murfatlar-to-device-test-to-shape-new-in-furrow soildivided $/ 3564 / 2019$

15. 1https://orbi.uliege.be/bitstream/2268/163965/1/Olivier.FIWAP.2012.pdf 